Original Research Paper

\title{
Castor Oil Based Epoxy/Clay Nanocomposite for Advanced Applications
}

\author{
Aditi Saikia and Niranjan Karak \\ Advanced Polymer and Nanomaterial Laboratory, Center for Polymer Science and Technology, \\ Department of Chemical Sciences, Tezpur University, Tezpur 784028, India
}

Article history

Received: 03-11-2015

Revised: $10-12-2015$

Accepted: 23-12-2015

Corresponding Author: Niranjan Karak

Advanced Polymer and Nanomaterial Laboratory, Center for Polymer Science and

Technology, Department of

Chemical Sciences, Tezpur

University, Tezpur 784028, India

Tel: +91-3712-267009;

Fax: +91-3712-267006

Email:karakniranjan@gmail.com

\begin{abstract}
Bio-based hyperbranched and linear epoxy resins were synthesized from monoglyceride of Ricinus communis oil. The nanocomposites of these hyperbranched and linear epoxies with 1,2 and 3 $\mathrm{wt} \%$ of OMMT were also fabricated. The structures of the resins and their nanocomposites were analyzed by FTIR, NMR, XRD, SEM and TEM. The studies of performance characteristics of poly(amido amine) cured thermosetting nanocomposites showed significant improvements in tensile strength from 5.8 to $11.9 \mathrm{MPa}$, impact from 80 to $>100 \mathrm{~cm}$, scratch resistance from 4 to $9 \mathrm{~kg}$, thermal stability from 213 to $316^{\circ} \mathrm{C}$ and chemical resistance over their pristine systems. Further, hyperbranched nanocomposites and bio-based epoxy thermosets exhibited better performance than the linear and petroleum based ones. The overall results, therefore, demonstrated hyperbranched epoxy/clay nanocomposites as potential materials for advanced applications.
\end{abstract}

Keywords: Hyperbranched Epoxy, Castor Oil, Clay Nanocomposites, Performance

\section{Introduction}

In the recent years, polymer nanocomposites have emerged as a most promising alternative to the traditional materials because of their intrinsic advantages such as easy process ability, light weight, reduce cost and tunable properties (Thakur and Kessler, 2015a; 2015b; Thakur et al., 2014a; Mechtali et al., 2014; Thakur and Thakur, 2014a). However, these polymeric materials are derived from petroleum based feedstocks which are non-renewable. Hence, to address such issues renewable bio-based polymers were developed by using bio-based starting material for their syntheses (Pappua et al., 2015; Thakur et. al., 2014b; Thakur and Kessler, 2014b; Chrysanthos et al., 2011).

Among the family of thermosetting polymers, epoxy thermosets have attained considerable attention in the area of coating, casting and adhesive applications because of their improved mechanical strength, good adhesive strength, high thermal stability, good chemical resistance and dimensional stability. However, in spite of such versatility, some of the disadvantages like low toughness, high brittleness and non-biodegradability restricting their utilizations in many advanced applications. Also, the global concern regarding the degradability of polymeric materials in environment compelled the scientists to explore the renewable resources in the production of useful materials (Velayutham et al., 2012; Yang et al., 2011; Biermann et al., 2000; Mungroo et al., 2008; Singh, et al., 2012). Therefore, to overcome such limitations, bio based epoxy resins were produced from vegetable oils. Vegetable oil is easily available, low cost, biodegradable material which provide flexibility to the resin and can be used for many industrial products such as adhesives, biodegradable biomaterials, etc. (Anastas and Eghbali, 2009; Lligadas et al., 2006; 2013). In recent times, hyperbranched polymers have attained great interest for their unique architectural features and properties. These hyperbranched polymers are highly branched, non-linear, non-entangled structures which exhibit outstanding characteristics like high solubility, low melt and solution viscosity, high reactivity, etc. Moreover, these polymers can be prepared by a single step process and thereby making them easy for large scale industrial production at reasonable cost. A large number of attempts have been made on the synthesis and characterization of 
hyperbranched epoxy resins (Jikei and Kakimoto, 2001; Chen and Yin, 2002). However, in most of the cases the performances such as toughness, mechanical strength, thermal stability, etc. obtained are not up to the mark to address many advanced applications. In this milieu, the application of proper combination of aliphatic as well as aromatic moieties and incorporation of suitable nanomaterials were found encouraging. Different nanomaterials, viz. carbon dots, silver nanoparticles, nano clay, etc. were used for this purpose (Mahapatra and Karak, 2009; De and Karak., 2013; Rao and Blanton 2008; Barua et al., 2015).

Amongst these, nano clay is the most widely studied. The improvement of the performance of these polymer/clay nanocomposites is because of the layered structure and high aspect ratio that allow efficient interactions between the epoxy and the interlayer galleries of the clay. This is reflected from the improvement in the load tolerance ability of the epoxy thermosets and hence, they are widely used in polymer nanocomposites (Paula and Robeson, 2008; Vaia and Giannelis, 2001).

In this connection, the current work is focused to address the shortcomings of conventional epoxy thermoset by fabricating a hyperbranched epoxy thermoset and its nanocomposite with organo-modified clay at different weight percentages. A linear epoxy thermoset and its nanocomoposite were also fabricated for the purpose of comparative studies.

\section{Experimental}

\section{Materials}

Castor oil (Ricinus communis) (Indian Drug House, India, acid value $5.4 \mathrm{mg} \mathrm{KOH} / \mathrm{g}$ ), glycerol (Rankem, India) and Organo Modified Montmorillonite (OMMT) (Sigma Aldrich, Germany) were used only after drying under vacuum. Bisphenol A (BPA) (recrystallized from toluene before use), epichlorohydrin, triethanol amine, sodium hydroxide, sodium sulfate and calcium oxide powder (Merck, India) were used for the preparation of the monoglyceride, resins and their nanocomposites.

\section{Preparation of Monoglyceride of Castor Oil}

The monoglyceride was prepared by the reported standard procedure. Concisely, castor oil $(0.03 \mathrm{~mol}$, $27.6 \mathrm{~g})$, glycerol (0.06 mol, $5.52 \mathrm{~g})$ and $\mathrm{CaO}(0.0184$ $\mathrm{g}, 0.05 \mathrm{wt} \%$ with respect to oil) were taken together in a three-neck round bottom flask equipped with a thermometer, a mechanical stirrer and a nitrogen inlet. The reaction was continued for $2 \mathrm{~h}$ in $\mathrm{N}_{2}$ atmosphere and the temperature was maintained at about $210-220^{\circ} \mathrm{C}$. In this reaction, calcium oxide was used as catalyst and the formation of monoglyceride was confirmed by checking its solubility in methanol. Finally, it was kept in a vacuum desiccator for $24 \mathrm{~h}$ prior to use for the removal of moisture.

\section{Preparation of Hyperbranched Epoxy Resin (HPBE)}

The vegetable oil based hyperbranched epoxy resin was synthesized from the castor oil by reacting BPA with epichlorohydrin (3 mol per hydroxyl group), triethanol amine and monoglyceride of the castor oil at $110^{\circ} \mathrm{C}$ with continuous stirring. BPA $(21.90 \mathrm{mmol}, 5 \mathrm{~g})$, monoglyceride (1.35 mmol, $0.5 \mathrm{~g}, 10 \mathrm{wt} \%$ of BPA), triethanol amine $(1.67 \mathrm{mmol}, 0.25 \mathrm{~g})$ and epichlorohydrin (154.63 mmol, $14.30 \mathrm{~g})$ were taken together in a $250 \mathrm{~mL}$ three-neck round bottom flask fitted with a water condenser and clamped over an oil bath. As the reaction temperature was reached to $80^{\circ} \mathrm{C}$, $5 \mathrm{~N}$ aqueous solution of $\mathrm{NaOH}(51.54 \mathrm{mmol}, 2.061 \mathrm{~g}$ ) was added slowly to it by a dropping funnel for the period of 40-45 min with continuous heating. During this addition process, the temperature of the reaction was attained to the desired level $\left(110^{\circ} \mathrm{C}\right)$ and the stirring was continued for $4 \mathrm{~h}$ by maintaining the same conditions. The reaction was then stopped, transferred to a separating funnel and allowed to settle into two phases at room temperature. The aqueous layer was drained out and organic layer was washed with distilled water followed by brine solution. Finally, the resin as sticky mass was separated out after drying with anhydrous $\mathrm{Na}_{2} \mathrm{SO}_{4}$. A little amount of THF was added to it then it was filtered off and finally dried by a rotary evaporator at $70^{\circ} \mathrm{C}$ under high vacuum to remove the volatiles including unreacted epichlorohydrin. A sticky, transparent product was obtained.

The linear epoxy was prepared by the same method with the same reactants without using triethanol amine. It was coded as LPE and used for the purpose of comparison.

\section{Preparation of Nanocomposite}

The Organically Modified Montmorillonite (OMMT) was first dried at $60^{\circ} \mathrm{C}$ in a vacuum oven for $24 \mathrm{~h}$. It was then mixed with the above epoxy resins by mechanical stirring followed by sonication. HBPE/clay nanocomposites were prepared by homogeneous mixing of desired amount of OMMT with epoxy resin to obtain 1,2 and $3 \mathrm{wt} \%$ of clay in the matrix. THF $(2 \mathrm{~mL})$ was added in each case to facilitate proper mixing of the components. The mixture was stirred magnetically for 3 $\mathrm{h}$ at $60^{\circ} \mathrm{C}$ followed by ultrasonication under $60 \%$ amplitude, 0.5 cycle and acoustic power density 460 $\mathrm{W} / \mathrm{cm}^{2}$ for $10 \mathrm{~min}$ in a sonicator. After that, poly(amidoamine) (50 wt $\%, 0.5 \mathrm{~g}$ per $\mathrm{g}$ of $\mathrm{g}$ of resin) was added to the nanocomposite, homogenously mixed at room temperature and finally coated on glass slides. The 
coated glass slides were then kept under vacuum at room temperature for overnight and then cured at $100^{\circ} \mathrm{C}$ for a particular period of time which was optimized by determining the swelling value of the cured films. These cured films were coded as HPBE and LPE (for linear and hyperbranched epoxy) and HNC A, HNC B and HNC C (for 1, 2 and $3 \mathrm{wt} \%$ of hyperbranched nanocomposites respectively). Similarly, LNC A was coded as linear epoxy nanocomposite with $1 \mathrm{wt} \%$ OMMT. For impact test, they were cast on steel plates (De and Karak, 2013).

\section{Instrumental and Testing Methods}

The FTIR spectra of the prepared resins as well as nanocomposites were studied in the range of 4000-500 $\mathrm{cm}^{-1}$ by a Nicolet FTIR spectrophotometer (Impact- 410, Madison, WI) using KBr pellets. The ${ }^{1} \mathrm{H}$ NMR and ${ }^{13} \mathrm{C}$ NMR spectra of the resins were also recorded by a 400 MHz FT-NMR (JEOL) spectrometer by using DMSO- $d_{6}$ as the solvent and TMS as the internal standard. The ultrasonication of the nanocomposites were carried out by UP200S, (Hielscher) ultrasonic processor with a 3 $\mathrm{mm}$ tip diameter standard sonotrode. The morphologies of the nanocomposites as well as the pristine thermosets were studied by the Scanning Electron Microscope, SEM (JEOL, JSM-6390 LV) and High Resolution Transmission Electron Microscope, HRTEM (JEOL, JEMCXII). The periodicity as well as interlayer spacing of polymer nanocomposites was calculated from XRD patterns of them as obtained by X-Ray Diffractometer Miniflex (Rigaku Corporation). The thermal properties were studied by the Thermogravimetric analyser (Shimazdu TG 50) and Differential Scanning Calorimeter (Perkin Elmer, DSC 6000) and the viscosity was tested by rheometer (Bohlin Instruments, Rheometer CVO, Malvern). The scratch resistance was tested by using a scratch hardness tester (Sheen instrument Ltd.). The gloss of the cured films was tested by making use of a glossmeter (Minigloss, Sheen Instrument Ltd.) with the angle of incidence at $60^{\circ}$ and the impact was tested with the help of an impact tester (S.C. Dey Co.,) by the standard falling ball method (ASTM D 1709). The tensile strength and elongation at break (standard ASTM D 882) experiments were measured by an Universal Testing Machine (UTM, WDW10) with $500 \mathrm{~N}$ load cell at a crosshead speed of $10 \mathrm{~mm} / \mathrm{min}$ ) (De and Karak, 2013; Barua et al., 2015).

\section{Results and Discussions}

\section{FTIR and NMR Analysis}

FTIR spectra of HPBE, HNC C and OMMT showed the following bands, Fig. 1: for $\operatorname{HPBEv}_{\max }\left(\mathrm{cm}^{-1}\right): 3457$ $(-\mathrm{OH}), 2971(-\mathrm{CH}), 1747(-\mathrm{C}=\mathrm{O}), 1608$ (aromatic $\mathrm{C}=$ C), 913 and 835 (epoxy ring); for HNC C: 3446 (-OH), $2930(-\mathrm{CH}), 1731(-\mathrm{C}=\mathrm{O}), 1602$ (aromatic $\mathrm{C}=\mathrm{C})$ and
910 and 831 (epoxy ring) and for OMMT: 3413 (-OH), 2913(-CH), 527 (Al-O-Si) and 461 (Si-O-Si). The ($\mathrm{OH})$ band around $3457 \mathrm{~cm}^{-1}$ in HPBE shifts to 3446 and $3413 \mathrm{~cm}^{-1}$ in case of HNC $\mathrm{C}$ and OMMT respectively. Also the $-\mathrm{C}=\mathrm{O}$ and aromatic $\mathrm{C}=\mathrm{C}$ stretch in HPBE shifts from 1747 and $1608 \mathrm{~cm}^{-1}$ to 1731 and $1602 \mathrm{~cm}^{-1}$ respectively in $\mathrm{HNC} \mathrm{C}$ which shows the interaction of OMMT with the epoxy. The OMMT shows bands at around 527 and $461 \mathrm{~cm}^{-1}$ which are due to the Al-O-Si and Si-O-Si stretch of clay which were absent in HNC C and HPBE.

The peak assignments of ${ }^{1} \mathrm{H}$ NMR of HPBE resin (Fig. 2), $\delta \mathrm{H}, \mathrm{ppm}\left(400 \mathrm{MHz}, d_{6} \mathrm{DMSO}, \mathrm{Me}_{4} \mathrm{Si}\right)$ are: 0.75-2.30 (fatty acid protons), $1.47\left(-\mathrm{CH}_{3}\right.$ protons of BPA), 2.61 and $2.73\left(-\mathrm{CH}_{2}\right.$ protons of oxirane ring), 3.21 (-CH proton of oxirane ring), 3.67 (monoglyceride central protons), 3.68 (protons attached with the -OH and ether linkages), 3.79 (protons attached with the substituted triethanol amine moiety), 3.91 (-OH proton), 4.15 (-CH proton attached with carbonyl group), 5.67 (Protons with $\mathrm{C}=\mathrm{C}$ bond), 6.75 and 7.01 (aromatic protons of BPA). Also, the peak assignments of ${ }^{13} \mathrm{C} N M R$ of HPBE resin (Fig. 3), $\delta \mathrm{C}$, ppm are: $44.24\left(-\mathrm{CH}_{2}\right.$ of the oxirane ring), 50.33 (-CH of the oxirane ring), 31.11 ($\mathrm{CH}_{3}$ of BPA), 41.60 (bisphenol-A unit), 69.12 and 69.24 (-OCH $\mathrm{OCH}_{2}$ group), 69.47 (-CHOH group), 63.29,65.94, 68.06 (mono, di and tri substituted triethanol amine ring), $115.16,127.92,143.44$ and 156.74 (four carbons of phenyl ring). From the ${ }^{13} \mathrm{C}$ NMR spectrum of HPBE resin, the integration ratio of Dendritic $(D)=0.84$, linear $(\mathrm{L})=0.34$ and Terminal $(\mathrm{T})=1$ moieties were obtained which provides the Degree of Branching (DB) as 0.84 . This value is in agreement with the range assigned for the hyperbranched polymer, i.e., $0.5-<1$.

\section{XRD Analysis}

From the XRD analysis (Fig. 4), a very sharp peak was observed for OMMT. This was due to the presence of ordered silicate layers. However, the same was diminished in the polymer nanocomposites. This may be due to the interactions of the layers with the polymer resulting into exfoliation (Barua et al., 2015), which is supported by TEM study.

\section{Morphological Study}

The SEM micrographs revealed the rough morphology of the nanocomposite (Fig. 5a and b). The roughness of the surface of the nanocomposite confirmed the interaction of the epoxy polymer with the silicate galleries of the nanoclay. The TEM micrograph (Fig. 6 and 7) of the HNC C nanocomposite showed partial exfoliation of the clay layers. This indicated further the presence of a strong interaction between the hyperbranched epoxy and the clay layers (De and Karak, 2014; Ho et al., 2006) . 


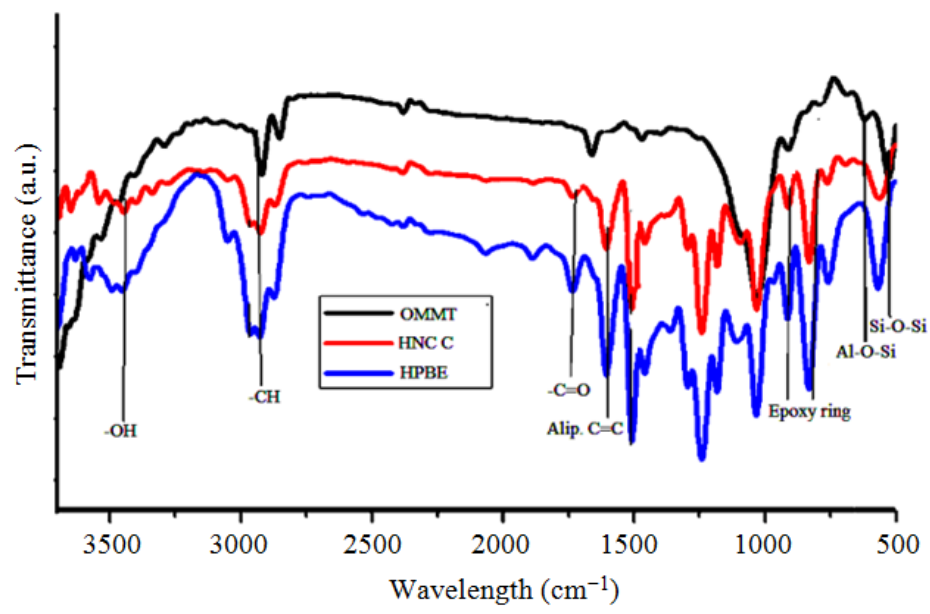

Fig. 1. FTIR spectra of HPBE, HNC C (before curing) and OMMT

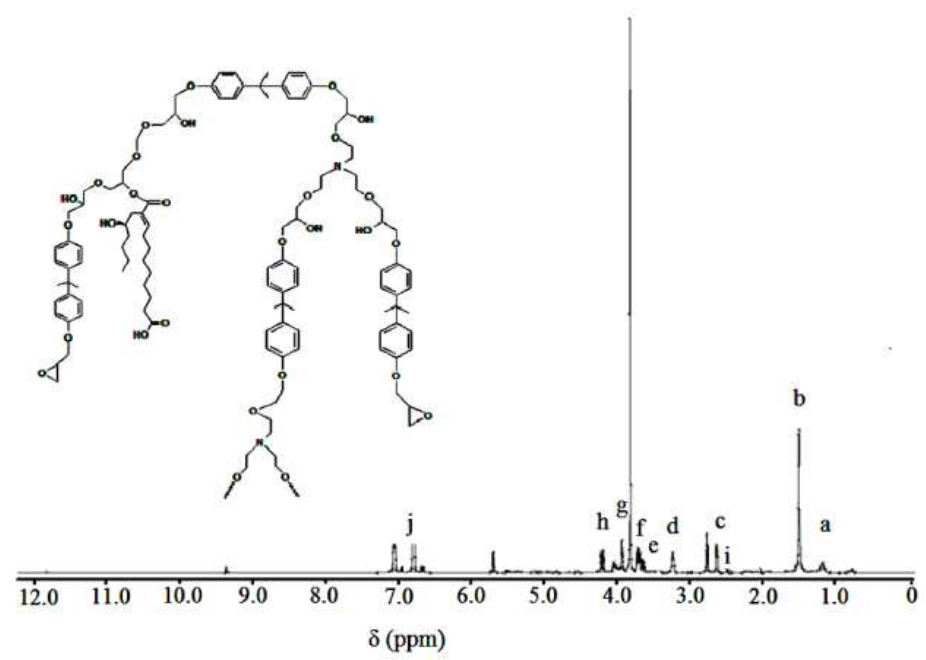

Fig. 2. ${ }^{1} \mathrm{H}$ NMR spectrum of HPBE resin

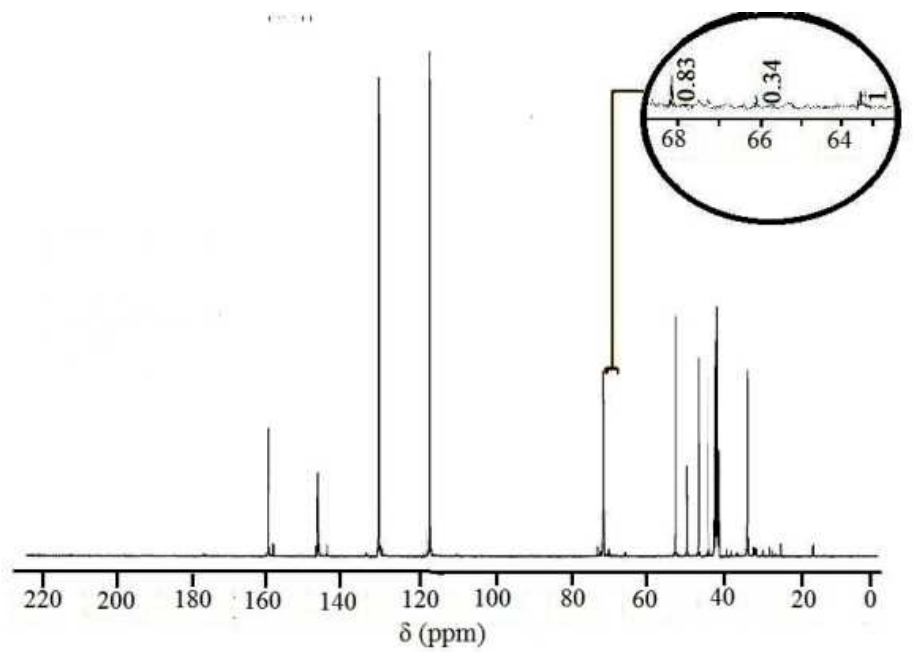

Fig. $3 .{ }^{13} \mathrm{C}$ spectrum of HPBE resin 


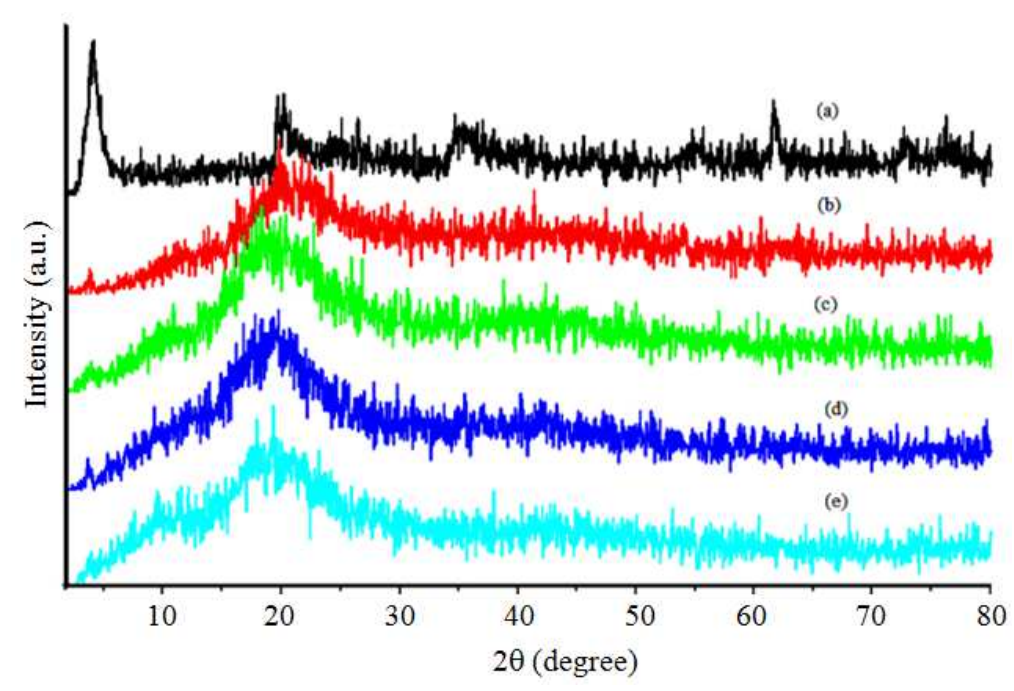

Fig. 4. XRD patterns of (a) OMMT, (b) HNC A, (c) HNC B, (d) HNC C and (e) HPBE
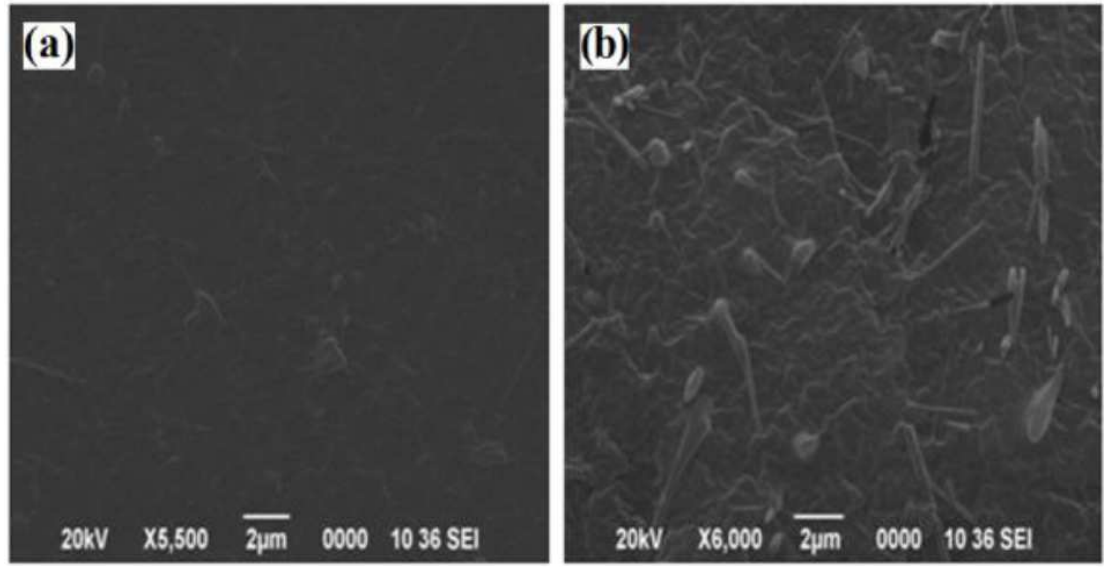

Fig. 5. SEM micrographs of (a) HPBE and (b) HNC C

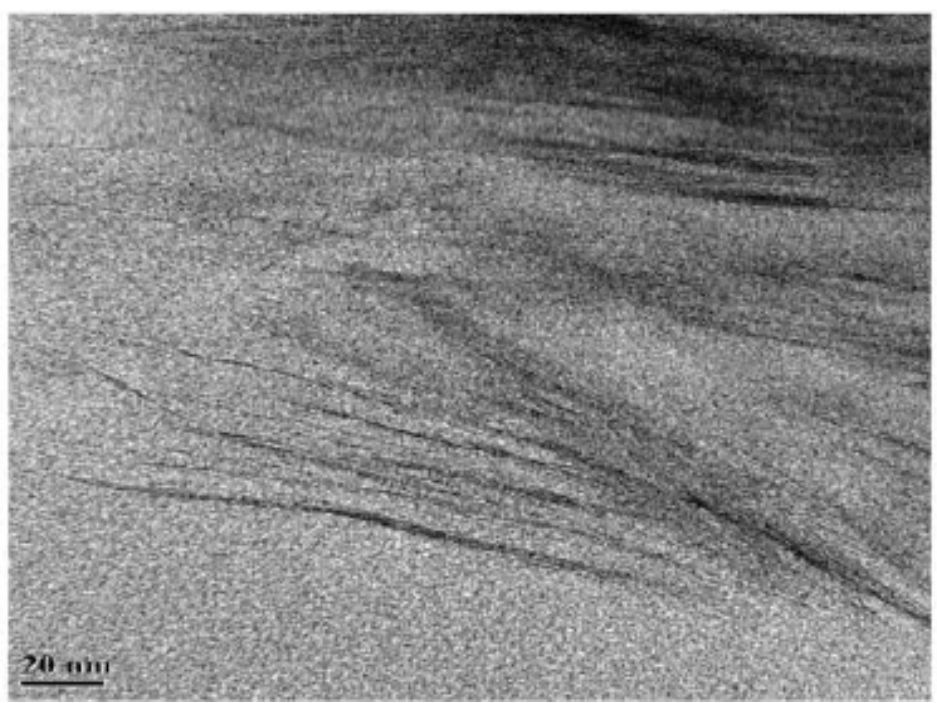

Fig. 6 TEM micrograph of $\mathrm{HNC} \mathrm{C}$ nanocomposite 
Table 1. Physical properties of the resins

\begin{tabular}{lll}
\hline Properties & LPE & HPBE \\
\hline Epoxy equivalent (g per eqv.) & 236 & 303 \\
Hydroxyl value (mg KOH per g) & 117 & 105 \\
Viscosity (Pa s) & 4.2 & 3.37 \\
\hline
\end{tabular}

\section{Physical Properties}

The physical properties like epoxy equivalent, hydroxyl value, etc. are tabulated in Table 1. From the table it was noticed that the epoxy equivalent as well as the hydroxyl value of the hyperbranched resin were found to be higher than that of the linear one because of the presence of the hyperbranched units with higher functionalities. The viscosity of the hyperbranched resin was lower than the linear resin which might be due to unique globular like shape of the former. The solubility of the resins were checked in different solvents and it was observed that the hyperbranched resin was soluble in organic solvents including THF, DMF, DMAc, DMSO, methanol, ethanol and xylene because of the globular shape and presence of large number of functionalities in the structures.

\section{Curing Study}

The resins were cured at $100^{\circ} \mathrm{C}$ and it was found that the curing time decreased with the increasing amount of OMMT. Also, the presence of hyperbranching in the resins influenced the rate of curing. Therefore, the hyperbranched resins having higher amount of OMMT showed faster rate of curing than pristine polymers. This curing process occurred due to the reaction between the oxirane groups of the epoxy with the labile hydrogen atoms of amino group of the hardener. This was further enhanced by the presence of OMMT. From the DSC curves (Fig. 9). It was observed that the enthalpy of HPBE was $-479 \mathrm{~J} / \mathrm{g}$ and $\mathrm{HNC} \mathrm{C}$ is $-285 \mathrm{~J} / \mathrm{g}$. The enthalpy of HNC C was much lower compared to the HPBE which was due to the absorption of thermal energy by nanoclay that provided stability to the matrix. Again, the curing time for HPBE and HNC C were found to be 9.56 and 7.75 min respectively. However, the actual times for curing of the respective articles were much higher than the values obtained from DSC studies. This is due to higher volume and insulating nature of the epoxy resins in the articles than in DSC pans.

\section{Mechanical and Thermal Studies}

From the Table 2, it was found that HNC C showed greater impact resistance compared to pristine resins which is due to the highly crosslinked as well as the presence of nanoclay and the flexible linkages of the aliphatic groups. The percentage of elongation decreased with the increase of the tensile strength. The cured films showed high tensile strength due to the presence of aromatic bisphenol A moiety and strong interactions which increased on increasing the amount of OMMT content. High gloss value was due to good dimensional stability and smooth surface of the thermosets. The value increased with the amount of OMMT in the nanocomposite due to the same reason. The scratch resistance of $\mathrm{HNC} \mathrm{C}$ was also high which might be due to the above mentioned reasons. All the results of mechanical studies were compared with the commercially available epoxy cured with poly(amido amine) coded as SBE. The results showed that the tensile strength of the commercially available epoxy was comparatively better than the rest of the thermosets. However, other properties, particularly elongation was extremely poor, might be due to brittle character of SBE.

The thermal stabilities were also studied for LPE, LNC C, HNC A, HNC B, HNC C and HPBE (Table 3) were found to be good as shown in Fig. 8. From this figure, two steps of major degradation in all the samples were noticed. The first step of degradation for HNC C and HPBE was at onset temperature of $316^{\circ} \mathrm{C}$ and $213^{\circ} \mathrm{C}$ respectively. The second step of degradation was at $398^{\circ} \mathrm{C}$ and $428^{\circ} \mathrm{C}$ for $\mathrm{HPBE}$ and HNC C respectively. Thus, HNC C is thermally more stable than the HPBE. HNC $\mathrm{C}$ is a nanocomposite containing $3 \mathrm{wt} \%$ of OMMT, a thermally stable insulator. The presence of OMMT in HNC C provides stability to the polymer due to the physico-chemical interaction occurring as a result of the intercalation of clay galleries with the polymer and poly (amidioamine). This results in restriction of segmental motion of the polymer chains. Hence, the presence of nanoclay and polymer gives higher thermostability to HNC $\mathrm{C}$ which is absent in HPBE and therefore its thermostabilty is low.

\section{Chemical Resistance Tests}

The weight loss of thermosetting epoxies and their nanocomposites in different chemical environments for 20 days was measured and the results are given in Table 4. From Table 4 it is seen that the hyperbranched thermosets exhibits good alkali and acid resistance than linear ones which is because of the compact structure with strong chemical linkages of the hyperbranched epoxy. Although the epoxy resins composed of hydrolyzable ester linkage in their structure but the alkali resistance was found to be very good this is due to the presence of diglycidyl ether of bisphenol $A$ as the terminal moieties that protected the internal ester linkage from the attack of alkali. Also the presence of nanoclay in the epoxy nanocomposites further enhanced the resistance against acid and alkali. The nanocomposites showed better alkali and acid resistance properties than their respective pristine system. 


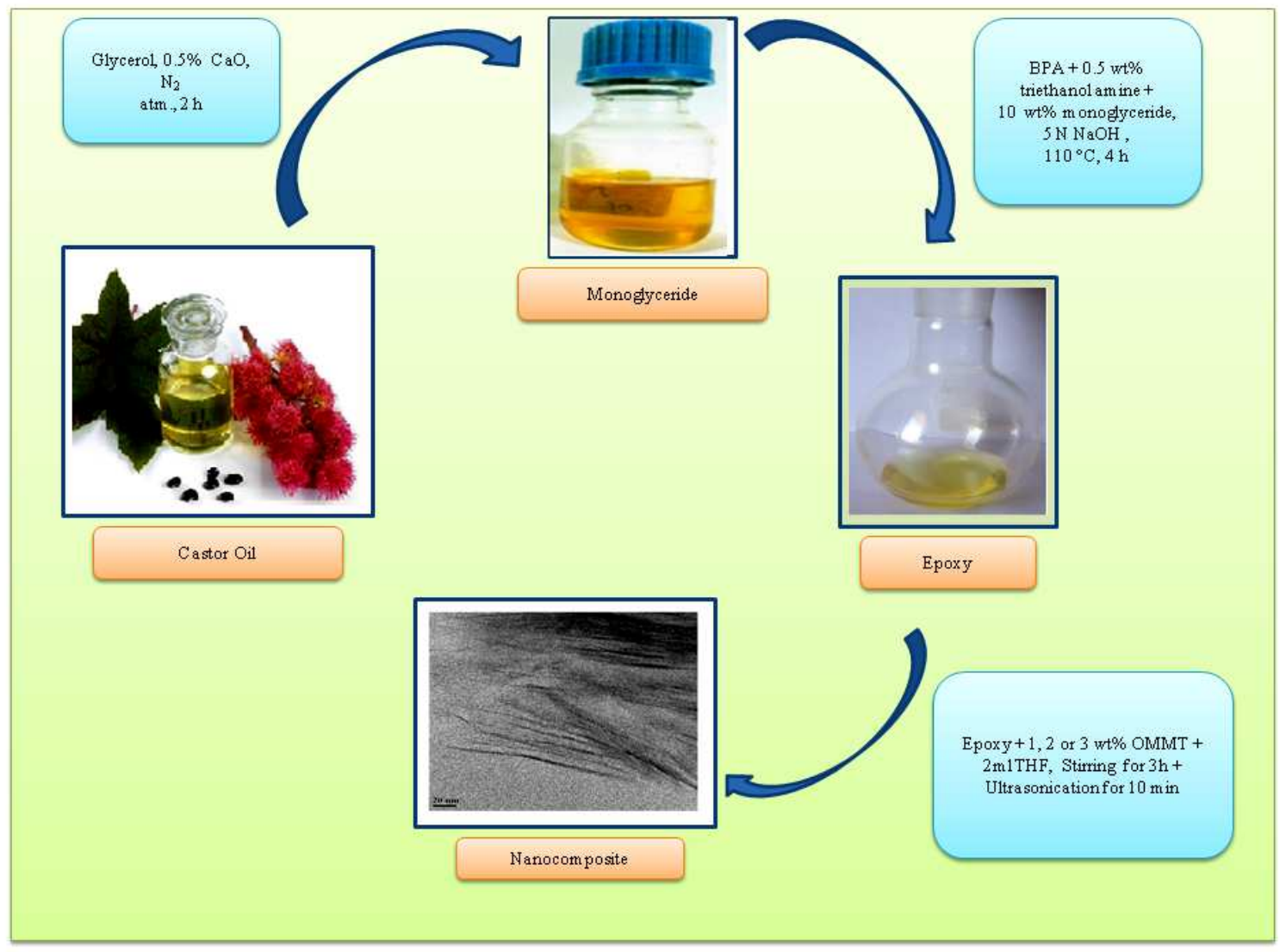

Fig. 7. Schematic illustration of formation of castor oil based hyperbranched epoxy/clay nanocomposite

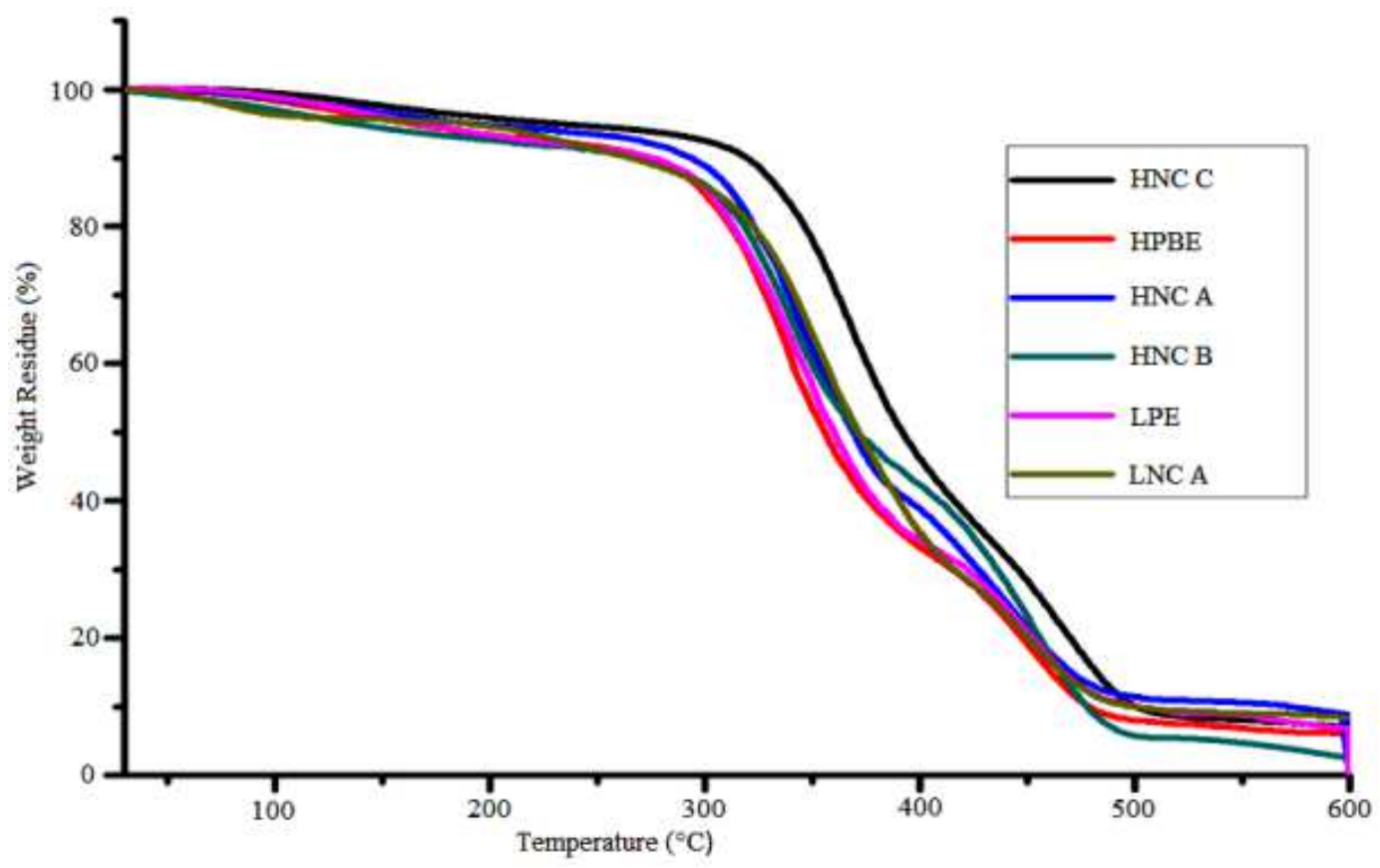

Fig. 8. TGA thermograms of HPBE and LPE and their nanocomposites 


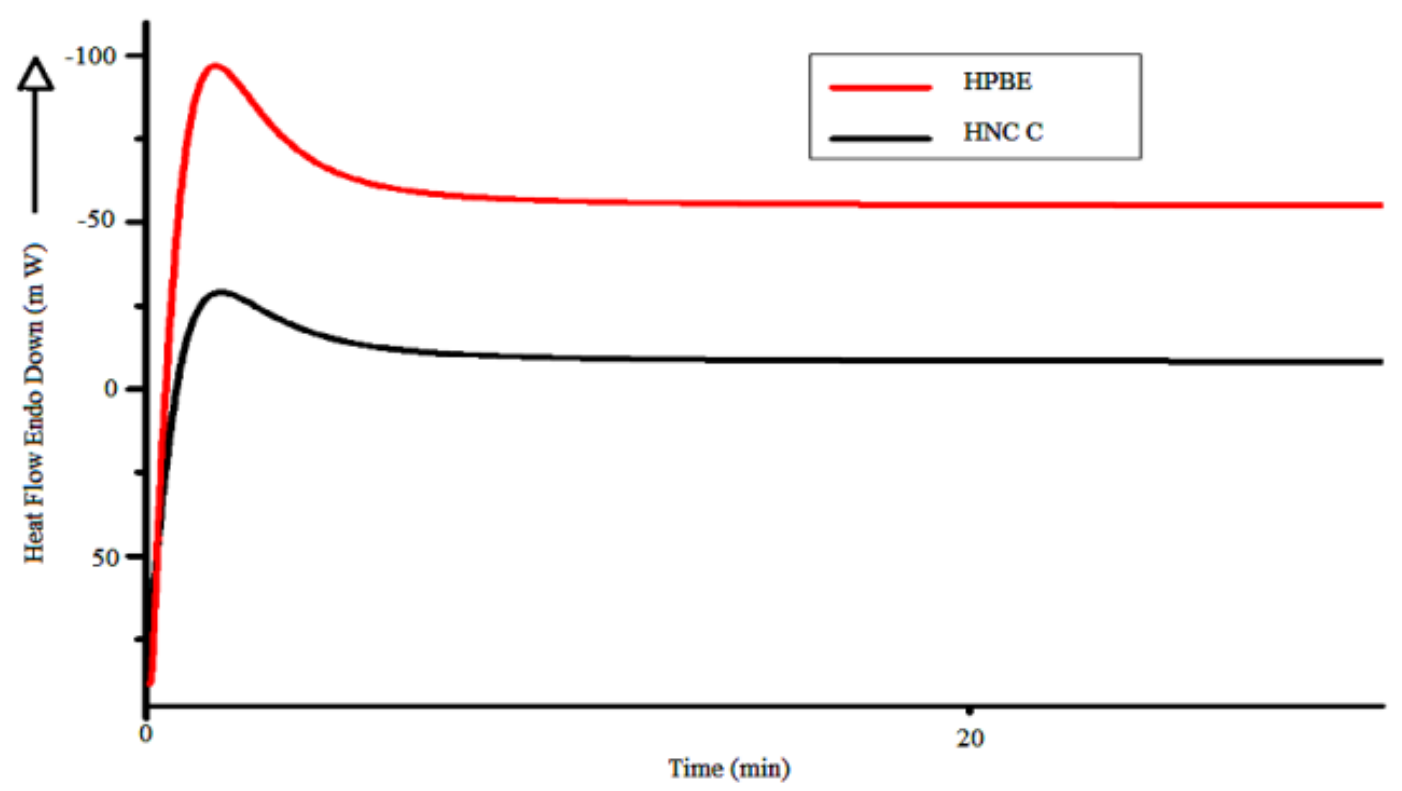

Fig. 9. DSC thermograms of HPBE and HNC C

Table 2. The mechanical tests of resins and the nanocomposites and their different compositions

\begin{tabular}{llllll}
\hline Sample name & $\begin{array}{l}\text { Tensile } \\
\text { Strength }(\mathrm{MPa})\end{array}$ & $\begin{array}{l}\text { Impact } \\
\text { Resistance }(\mathrm{cm})\end{array}$ & $\begin{array}{l}\text { Elongation } \\
(\%)\end{array}$ & $\begin{array}{l}\text { Scratch } \\
\text { Resistance }(\mathrm{kg})\end{array}$ & $\begin{array}{l}\text { Gloss } \\
\left({ }^{\circ} \mathrm{C}\right)\end{array}$ \\
\hline LPE & 6.4 & 60 & 16 & 4.0 & 70.4 \\
HPBE & 5.8 & 80 & 44 & 6.5 & 61.6 \\
LNC A & 9.0 & 70 & 42 & 4.0 & 74.3 \\
HNC A & 6.8 & 80 & 35 & 6.0 & 75.5 \\
HNC B & 7.9 & 100 & 48 & 8.5 & 87.0 \\
HNC C & 11.9 & $>100^{*}$ & 24 & 9.0 & 85.0 \\
SBE* & 38.0 & 65 & 5 & 7.0 & - \\
\hline
\end{tabular}

*Instrument limit is 100

*Data reported from De and Karak, 2014.

Table 3. Thermal degradation parameters for pristine thermosetting epoxy and nanocomposites

\begin{tabular}{lllll}
\hline Samples & $\begin{array}{l}\text { Initial Degradation } \\
\text { Temperature }\left({ }^{\circ} \mathrm{C}\right)\end{array}$ & $\begin{array}{l}\text { Degradation } \\
\text { Temperature for } \\
50 \mathrm{wt} \%\left({ }^{\circ} \mathrm{C}\right)\end{array}$ & $\begin{array}{l}\text { Temperature for } \\
\text { maximum rate of } \\
\text { degradation }\left({ }^{\circ} \mathrm{C}\right)\end{array}$ & $\begin{array}{l}\text { Weight Residue } \\
\text { at } 600^{\circ} \mathrm{C}(\%)\end{array}$ \\
\hline HPBE & 213 & 398 & 333 & 6.80 \\
HNC A & 300 & 402 & 337 & 7.70 \\
HNC B & 302 & 410 & 337 & 4.09 \\
HNC C & 316 & 428 & 366 & 9.23 \\
LPE & 202 & 395 & 330 & 6.50 \\
LNC A & 304 & 405 & 342 & 8.90 \\
SBE & 200 & 415 & - & - \\
\hline
\end{tabular}

Table 4. Chemical resistance of resins and the nanocomposites

\begin{tabular}{llllll}
\hline Chemical Environment & LPE & HPBE & HNC A & HNCB & HNC C \\
\hline Aq. $\mathrm{NaOH}(5 \%)$ & 3.08 & 2.16 & 0.47 & 0.58 & 0.95 \\
Aq. $\mathrm{HCl}$ & & & & & \\
$(5 \%)$ & 2.81 & 2.38 & 0.23 & 0.70 & 0.53 \\
Aq. $\mathrm{NaCl}(10 \%)$ & 1.67 & 2.24 & 0.55 & 0.87 & 0.76 \\
Water & 0.00 & 0.00 & 0.00 & 0.00 & 0.00 \\
\hline
\end{tabular}




\section{Conclusion}

In the present study a simple approach is demonstrated to obtain thermosetting nanocomposites with good mechanical properties, good thermal stability and high chemical resistance which help to overcome the drawbacks of conventional epoxy nanocomposites like high brittleness and low toughness characteristics. The optimization of curing time and swelling study showed that the hyperbranched resins and their nanocomposites displayed better results compared to the linear ones. The morphological and orderness studies of the resins and their nanocomposites by SEM and XRD indicate the presence of interaction of polymer chains with the OMMT. However, TEM studies showed that the clay layers are partially exfoliated by the polymer chains. The mechanical properties of cured resins were found to be enhanced with the increasing percentage of OMMT. Overall, HNC C showed better results compared to the others. Thermal study helped to conclude that the epoxy/clay nanocomposites were more thermally stable compared to the pristine polymer which was due to the presence of nanoclay in the polymer matrix that offered good thermal resistance. Further, the nanocomposites showed better chemical resistance in different chemical environments than LPE and HPBE.

\section{Acknowledgement}

The authors of this work would like to offer sincere gratitude and thanks to Sophisticated Analytical Instrument Facility (SAIF), North-Eastern Hills University (NEHU), Shillong, for performing TEM analysis of the samples.

\section{Author's Contributions}

Aditi Saikia: Performed all the experiments, synthesized the nanocomposite, evaluated the data and contributed to the writing of the manuscript.

Niranjan Karak: Conceived and designed the plan of work, the experiments and contributed to the writing of the manuscript.

\section{Ethics}

This work is purely original and no part of it has been published earlier anywhere in any form.

\section{References}

Anastas, P. and N. Eghbali, 2009. Green chemistry: Principles and practice. Chem. Soc. Rev., 39: 301-312. DOI: 10.1039/b918763b
Barua, S., P. Chattopadhyay, L. Aidew, A.K. Buragohain and N. Karak, 2015. Infection-resistant hyperbranched epoxy nanocomposite as a scaffold for skin tissue regeneration. Polym. Int., 64: 303-311. DOI: $10.1002 /$ pi.4790

Biermann, U., W. Friedt, S. Lang, W. Lühs and G. Machmüller et al., 2000. New syntheses with oils and fats as renewable materials for chemical industry. Angew. Chem. Int. Ed., 39: 2206-2224. DOI: 1433-785/00/3913-2207

Chen, H. and J. Yin, 2002. Synthesis and characterization of hyperbranched polyimides with good organosolubility and thermal properties based on a new triamine and conventional dianhydrides. J. Polym. Sci., Part A, 40: 3804-3814. DOI: $10.1002 /$ pola. 10475

Chrysanthos, M., J. Galy and J.P. Pascault, 2011. Preparation and properties of bio-based epoxy networks derived from isosorbidediglycidyl ether. Polymer, 52: 3611-3620.

DOI: 10.1016/j.polymer.2011.06.001

De, B. and N. Karak, 2013. Novel high performance tough hyperbranched epoxy by an A2+B3 polycondensation reaction. J. Mater. Chem. A., 1: 348-353. DOI: $10.1039 / \mathrm{c} 2 \mathrm{ta} 00011 \mathrm{c}$

De, B. and N. Karak, 2014. Tough hyperbranched epoxy/poly(amido-amine) modified bentonite thermosetting nanocomposites. J. Appl. Polym. Sci., 131: 4087-4087. DOI: 10.1002/APP.40327

Ho, M.W., C.K. Lam, K.T. Lau, D.H.L. Ng and D. Hui, 2006. Mechanical properties of epoxy-based composites using nanoclays. Compos. Struct., 75: 415-421. DOI:10.1016/j.compstruct.2006.04.051

Jikei, M. and M. Kakimoto, 2001. Hyperbranched polymers: A promising new class of materials. Prog. Polym. Sci., 26: 1233-1285.

DOI: $10.1016 / \mathrm{S} 0079-6700(01) 00018-1$

Lligadas, G., J.C. Ronda, M. Galià and V. Cádiz, 2006. Bionanocomposites from renewable resources: Epoxidized linseed oil-polyhedral oligomeric silsesquioxanes hybrid materials.

Biomacromolecules, 7: 3521-3526.

DOI: $10.1021 / \mathrm{bm} 060703 \mathrm{u}$

Lligadas, G., J.C. Ronda, M. Galià and V. Càdiz, 2013. Renewable polymeric materials from vegetable oils: A perspective. Mater. Today, 7: 3521-3526. DOI: $10.1016 /$ j.mattod.2013.08.016

Mahapatra, S.S. and N. Karak, 2009. Hyperbranched polyamine/Cu nanoparticles for epoxy thermoset. J. Macromol. Sci., Part A, 46: 296-303.

DOI: $10.1080 / 10601320802637375$ 
Mechtali, F.Z.E., H. Essabir, S. Nekhlaoui, M.O. Bensalah and M. Jawaid et al., 2014. Mechanical and thermal properties of polypropylene reinforced with almond shells particles: Impact of chemical treatments. J. Bionic Eng., 12: 2483-2494. DOI: $10.1016 / \mathrm{S} 1672-6529(14) 60139-6$

Mungroo, R., N.C. Pradhan, V.V. Goud and A.K. Dalai, 2008. Epoxidation of canola oil with hydrogen peroxide catalysed by acidic ion exchange resin. J. Am. Oil Chem. Soc., 85: 887-896. DOI 10.1007/s11746-008-1277-z

Pappua, A., V. Patil, S. Jain, A. Mahindrakar and R. Haquea et al., 2015. Advances in industrial prospective of cellulosic macromolecules enriched banana biofibre resources: A review. Int. J. Biol. Macromol., 79: 449-458.

DOI: 10.1016/j.ijbiomac.2015.05.013

Paula, D.R. and L.M. Robeson, 2008. Polymer nanotechnology: Nanocomposites. Polymer, 49: 3187-3204. DOI: 10.1016/j.polymer.2008.04.017

Rao, Y. and T.N. Blanton, 2008. Polymer nanocomposites with a low thermal expansion coefficient. Macromolecules, 41: 935-41. DOI: $10.1021 / \mathrm{ma} 7020216$

Singh, A., K. Yadav and A.K. Sen, 2012. Sal (Shorea Robusta) leaves lignin epoxidation and its use in epoxy based coatings. Am. J. Poly. Sci., 2: 14-18. DOI: $10.5923 /$ j.ajps.20120201.03

Thakur, V.K. and M.K. Thakur, 2015a. Recent advances in green hydrogels from lignin: A review. Int. J. Biol. Macromol., 72: 834-847.

DOI: 10.1016/j.ijbiomac.2014.09.044
Thakur, V.K. and M.R. Kessler, 2015b. Self-healing polymer nanocomposite materials: A review. Polymer, 69: 369-383.

DOI: $10.1016 /$ j.polymer.2015.04.086

Thakur, V.K. and M.K. Thakur, 2014a. Recent advances in graft copolymerization and applications of chitosan: A review. ACS Sustain. Chem. Eng., 2: 2637-2652. DOI: 10.1021/sc500634p

Thakur, V.K. and M.R. Kessler, 2014b. Synthesis and characterization of AN-g-SOY for sustainable polymer composites. ACS Sustain. Chem. Eng., 2: 2454-2460. DOI: $10.1021 / \mathrm{sc} 500473 \mathrm{a}$

Thakur, V.K. and M.K. Thakur and R.K. Gupta 2014a. Review: Raw natural fiber-based polymer composites. Int. J. Polym. Anal. Charact., 19: 256-271. DOI: 10.1080/1023666X.2014.880016

Thakur, V.K., D. Vennerberg and M.R. Kessler, 2014b. Green aqueous surface modification of polypropylene for novel polymer nanocomposites. ACS Appl. Mater. Interfaces, 6: 9349-9356. DOI: $10.1021 / \mathrm{am} 501726 \mathrm{~d}$

Vaia, R.A. and E.P. Giannelis, 2001. Polymer nanocomposites: Status and opportunities. MRS Bull., 26: 394-401. DOI: 10.1557/mrs2001.93

Velayutham, T.S., W.H.A. Majid and S.N. Gan, 2012. Dielectric behaviour of polyurethane coatings derived from palm oil oleic acid-based polyols-a renewable resource. J. Oil Palm Res., 24: 1260-1266.

Yang, Y., Y. Yua, Y. Zhanga, C. Liu and W. Shi et al., 2011. Lipase/esterase-catalyzed ring-opening polymerization: A green polyester synthesis technique. Process Biochem., 46: 1900-1908.

DOI: 10.1016/j.procbio.2011.07.016 